\title{
Circuit
}

Musiques contemporaines

\section{Hommage : Serge Garant, être de rigueur et d'émotion}

\section{Gilles Tremblay}

Volume 5, numéro 1, 1994

Gilles Tremblay : réflexions

URI : https://id.erudit.org/iderudit/902095ar

DOI : https://doi.org/10.7202/902095ar

Aller au sommaire du numéro

Éditeur(s)

Les Presses de l'Université de Montréal

ISSN

1183-1693 (imprimé)

1488-9692 (numérique)

Découvrir la revue

Citer cet article

Tremblay, G. (1994). Hommage : Serge Garant, être de rigueur et d'émotion. Circuit, 5(1), 65-68. https://doi.org/10.7202/902095ar d'utilisation que vous pouvez consulter en ligne.

https://apropos.erudit.org/fr/usagers/politique-dutilisation/ 


\section{Serge Garant, être de rigueur et d'émotion}

Paru dans le dossier In Memoriam Serge Garant, préparé par Marcelle Guertin, Revue de musique des universités canadiennes, $n^{\circ} 7,1986$, pp. 22-24.

Très cher ami et compagnon de route! Faut-il parler de toi au passé, toi le passionné du présent, là où se manifeste la musique en ce temps où nous restons, bouleversés?

C'est chez moi que nous nous sommes rencontrés pour la première fois avec François Morel et Roger Matton qui tenaient à nous présenter ce musicien phénoménal de Sherbrooke. Nous étions alors dans la jeune vingtaine et venions de découvrir Varèse. Arrivant de Paris, tu apportais dans ta serviette des partitions de Messiaen, de Webern, alors à peu près inconnus ici, ainsi que du jeune Boulez. Tu nous parlais aussi de Stockhausen. Ce fut une journée exaltante. Lisant, jouant, improvisant au piano, en une sorte de passion juvénile où, questions, doutes, critiques, adhésion entremêlés, soufflait l'enthousiasme. De plus, nous avions l'impression de nous mettre à l'heure du monde. Basé sur cette ferveur partagée, tel fut le point de départ de notre amitié, une amitié assez solide pour se permettre toutes les divergences. Nos chemins différaient, mais à chaque croisée, un accord profond nous réunissait tacitement, sans que nous ayons besoin de l'expliciter.

Au nom de tous tes amis, collaborateurs et collaboratrices, proches ou lointains, je tiens à te rendre hommage pour ce don d'amitié.

Chef d'orchestre, membre fondateur et directeur artistique de la Société de musique contemporaine depuis vingt ans, pédagogue, professeur à l'Université de Montréal, commentateur à la radio, toutes ces activités dérivaient du 
fait que tu étais avant tout compositeur. Et c'est à celui-ci qu'il faut surtout rendre hommage pour la très haute exigence et la rigueur que tu avais envers toi-même, soucieux de netteté et d'exactitude. Être d'émotion, tu aimais dire: "L'émotion, bien sûr que ça existe, mais j'ai horreur d'en parler ». Le lyrisme de pudeur qui t'est propre $n^{\prime}$ en est que plus éloquent.

Quant au chef d'orchestre, tous les musiciens qui ont travaillé sous ta direction ont loué ta technique d'une rare clarté. Mais le contact était aussi d'un autre ordre: les musiciens t'aimaient.

Pour les compositeurs, travailler avec un tel chef devenait une collaboration de tous les instants. Serge Garant est sûrement le chef de ce pays qui a monté le plus d'œuvres nouvelles d'ici et de l'étranger. Associés à ceux d'ici, les témoignages de Pierre Boulez, Gilbert Amy, Claude Ballif, Xenakis, Claude Helffer, François-Bernard Mâche, Marius Constant, Mariano Etkin, Norma Beecroft, John Beckwith, Robert Aitken, et de plusieurs autres qui nous arrivent, expriment leur consternation et leur reconnaissance.

Je tiens aussi à mentionner, en présence de ses frères et sœurs, l'importance qu'avait sa famille pour lui, surtout ces dernières années. N'est-ce pas vous tous qui, avec ses intimes les plus dévoués, louise Hirbour, Jean-Paul Néron, l'avez assisté dans cette mort très douce? Serge m'avait quelquefois parlé aussi de son père, qui fut membre de l'Harmonie de Sherbrooke, et de sa mère qui était, paraît-il, une excellente musicienne.

Serge Garant s'était vu décerner plusieurs honneurs et décorations, dont le Prix Calixa-Lavallée de la Société Saint-Jean-Baptiste et le Prix Jules-Léger, pour ne citer que ceux-là. II venait également d'être reçu membre de la Société Royale du Canada. Si ces événements ont un sens certain, ne serait-ce que celui de la reconnaissance, ils restent malgré tout extérieurs aux véritables événements qui se passent dans le secret le plus intime et dans la solitude : une idée qui naît, l'engagement de la volonté, ce dont on ne parle jamais mais qui mérite d'être mentionné avec le plus grand respect.

Pendant sa longue maladie, Serge Garant a reçu de nombreuses lettres d'amis, de collègues, et surtout d'élèves anciens ou récents. Il a été surpris de découvrir qu'on l'aimait à ce point et cela l'a aidé, a-t-il dit, à supporter l'épreuve de ces derniers mois. Parmi ceux qui ont compati à sa maladie, un de nos collaborateurs nous a également quittés il y a trois mois: je voudrais en ce jour associer Daniel Sarijian à ce tissu d'amour. 
C'est en Adam, dit Saint Paul, que meurent tous les hommes; c'est dans le Christ que tous revivront, mais chacun en son rang: en premier le Christ; et ensuite, ceux qui seront au Christ lorsqu'il reviendra. Alors, tout sera achevé, quand le Christ remettra son pouvoir royal à Dieu le Père, après avoir détruit toutes les puissances du mal. C'est lui en effet qui doit régner jusqu'au jour où il aura mis sous ses pieds tous ses ennemis. Et le dernier ennemi qu'il détruira, c'est la mort, car il a tout mis sous ses pieds.

I, Cor, 15, 2-27a 


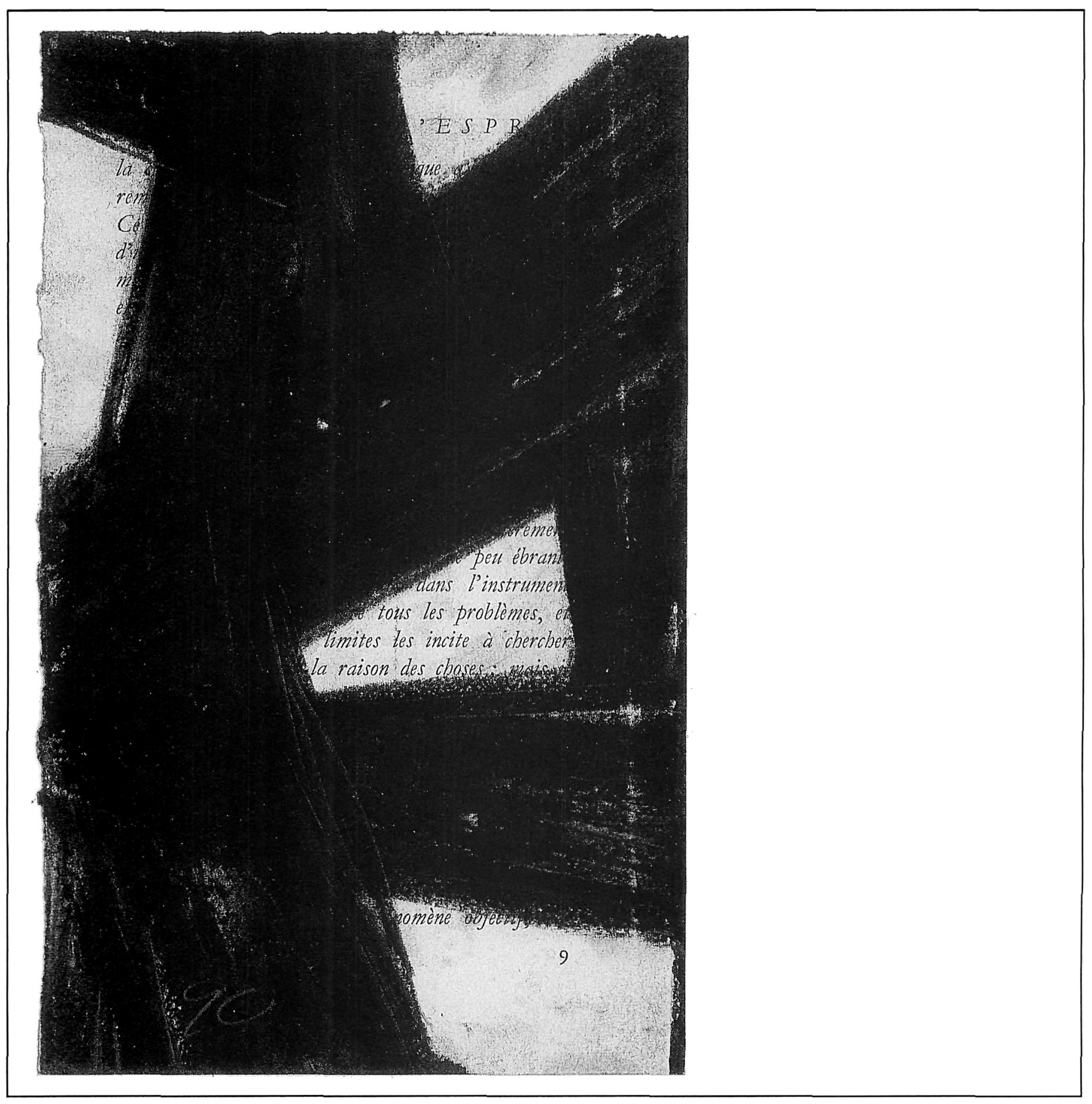

